\title{
Importance of Interpersonal Skills at Work towards Managing People in an Educational Context
}

\author{
Li-Na ZHANG* \\ Teachers' College Shenyang University, Shenyang City, Liaoning Province, China \\ 1402678739@qq.com \\ ${ }^{*}$ Corresponding author
}

Keywords: Interpersonal skills, Importance, Educational work.

\begin{abstract}
In this digital information age, more and more people are over-dependent on electronic communication, such as e-mail, voice mail audio-conferencing and video-conferencing. Simultaneously another challenge to many people has emerged with the question: how does it happen that people with high IQ (intelligence quotient) and electronic technologies do not always land top jobs even ordinary ones? The answer often lies in 'the $21^{\text {st }}$ Century Skill' -- interpersonal skills (the en Gauge $21^{\text {st }}$ Century skills 2003). As the recent ICT Skills Snapsho reveals: "As the demand data has shown, interpersonal skills (particularly communication skills) are mandatory" (Information Age 2004). Therefore, the significance of how people interact with one another at work has now widely been recognized, more especially in face-to-face interaction compared to the world of virtual communication. Effective interpersonal skills have become a vital part of professional contexts.
\end{abstract}

\section{Introduction}

This Paper discusses the importance and significance of interpersonal skills with reference to managing people in an educational context. It has four parts. Firstly, an outline to introduce the different theories and methodologies of interpersonal skills at work. Secondly, it provides the reasons why interpersonal skills and relationships in educational work context are important and getting more important. Thirdly, it explores examples of the utilization of interpersonal skills in different interpersonal relationships in an educational organization. Lastly, the conclusion comes, relating the evidence drawn from the literature and the findings from the case of educational organization.

\section{Interpersonal Skills and Their Elements}

\section{What are Interpersonal Skills?}

It is useful to examine exactly what is meant by the term 'Interpersonal skills'. 'Interpersonal skills' as a term is broadly similar to social skills and social competence, which are sometimes used interchangeably. Because of its ubiquitous nature, there is no single accepted definition of this term.

Because much of professional life is concerned with human relationships, Fontana (1990:1) defines social skills as the way in which people can effectively manage their professional relationships. He believes that, human relationships in many professionals, such as teachers, nurses, doctors, social workers, managers, lawyers and counselors, etc. are one of the key factors in determining the success or otherwise of professional performance (Fontana 1 990:1).

Some definitions lean towards viewing social skills as a competence that the individual may possess to a greater or lesser extent. Argyly (1984) defines socially competent people as those who possess skills necessary to produce desired effects on other people in social situations (Argyly, M. 1984. cited in Hayes, J. 2002: 3). This argument can also be found in the definition given by Schlundt and McFall (1985) who define social skills as 'the specific component processes' that enable an individual to behave in a manner that will be judged as "competent". It is clear that these 
definitions focus on the ability to behave in ways that amplify the likelihood of achieving desired outcomes.

Furthermore, other theorists, who define social skill in terms of the behaviour of the individual, have presented a somewhat different slant. McGuire and Priestley regard social skills as 'those kinds of behaviour which are basic to effective face-to-face communication between individuals' (1981: 6 cited in Hargine et a1.1987: 2). Hayes (2004:3) extends this behavioural highlighting, to include the goals of the individual, when he defines interpersonal skills as goal-directed behaviours used in face--to--face interactions in order to bring about a desired state of affairs. He thinks interpersonal or social behaviours are central to achieving the goals of interactive participants.

\section{What Comprises Interpersonal Skills?}

The study of interpersonal or social skills is complicated and multifaceted, encompassing interpersonal relationships, social competence, and interactive behaviours as suggested in the literature above. Thus, the components of interpersonal or social skills also originate from these different studies. Much of it concerns interpersonal relationships and interaction. Guirdham (2002) regards interpersonal communication skills as essential interpersonal skills to realize effective interpersonal relationships and interactive behaviour, ' ... we need to try to understand values, goals, emotions, beliefs, attitudes, intentions, abilities and traits, ... an ability to, recognize the meanings of emotions and being able to 'tune in' to other people's feelings, and to manage our own, are essential interpersonal skills'. Not surprisingly, there are numerous definitions of communication (Dance \&Larson, 1976 cited in Burgoon, et al 1994:1 8). Basically, to communicate is to send and receive messages using a mutually intelligible symbol system, involving both verbal and non-verbal behaviour, such as listening, speaking, writing and non-verbally by facial expressions, gestures, posture, vocal cues and appearance as well as behaviour. Egan (1998) identifies four basic communication skills:

1. attending, which refers to the way listeners orient themselves to speakers,

both physically and psychologically;

2. 1istening, which involves receiving and understanding the verbal and

non-verbal massages transmitted by speakers;

3. empathy, which involves listeners understanding messages from within

the speakers' frames of reference and communicating this to them;

4. probing, which involves encouraging and prompting speakers to

talk about themselves and to define their concern in more concrete

and specific terms.(Egan,1998.cited in Hayes,J.2002:54)

High-quality communication is effective and appropriate, which is able to produce the effects intended by the communicators and makes sense to the receiver in terms of wording, statements and logic (Guirdham, 2002:267).

Another core element of interpersonal or social skills is self-awareness. Forrest argues that to be effective in interpersonal skills, it is important to recognize one's own motives, experiences and prejudices and to be aware of how other people see us(Forrest,J.1989:3). Hayes considers that self-awareness can contribute to interpersonal competence: our awareness of self is closely linked to our ability to read the behaviour of others, construct a course of action and deliver an effective performance (Hayes, J.2002:32). Therefore, it is obvious that awareness of ourselves shows us how other people perceive us and how they will react to us. The third component of interpersonal skills is to understand others. In people's social life, interacting with other people is universally inevitable. When people want to get on well with one another at work or elsewhere, they usually have to interpret their speech and actions, including what they are saying and what they are doing. That is to say, to interact effectively, such as communicating appropriately, awareness of self and others as well as working with them in relationship, people must learn what others are thinking and feeling, including their motives, beliefs, attitudes and intentions (Guirdham, M. 2002:1 6 1). Skills, strategies and techniques for understanding others are listed: 
1. attending to others and interpreting verbal and non-verbal cues they provide;

2. making attributions, deciding the 'cause' of what someone is doing;

3 .forming judgments and impressions, deciding that a person's behaviour

reflects some aspect of their personality and unified personality impressions;

4. being aware of culture, ethnic and gender influences;

5. thinking about how the other person may be 'framing', or making their own

sense of a particular situation.(ibid)

In the literature review such as shown above as to interpersonal or social skills theorists such as Guirdham, Hayes and Forrest identified three main core skills of interpersonal skill as comprising effective interpersonal communication skills, awareness of self and others' skills and understanding others' skills. They are 'core' skills because of their basis of all human interaction, both in personal and professional lives.

\section{Why are Interpersonal Skills Important in Educational Work?}

Undoubtedly, all the interpersonal skills mentioned above are dependent on one another at work, not in isolation and cannot exist without reference to the specific context. They lie in not only the understanding of people, relationships and work but also the organizational context in which it takes place. Furthermore, it would, therefore, seem that learning when to employ these core skills is just as crucial as learning what these are and how to use them (Hargie, et a1.1981:5).

It is well-known that educational organizations are more people-oriented than others, such as factories with production lines. Dealing with people, including principals, colleagues, students well as parents, is inevitable in all work-based activities. It is an area in which more head is needed than heart. Interpersonal skills are demanded in educational work. They affect just about everything people do in educational organizations. It is obvious that individuals' interpersonal skills play an indispensable role in the daily communication and interactive behaviour in educational work.

Firstly, in educational organization work, interpersonal skills can be thought of as 'the oil in the engine', as 'the cornerstone of organizational functioning', which can focus on positive feelings such as confidence and congeniality as well as on the spirit of teamwork. Relationships and interactive behaviours without skills can lead to negative feelings, such as self-doubt and annoyance as well as the lack of internal co-operation and co-ordination, even destructive conflict.

Secondly, the core purpose of school is learning for students, teachers, principals and parents. Interpersonal skills can encourage this core activity. Because they contribute to appropriate, successful, supportive behaviour built around humanity, interpersonal skills get the results in confidence, self-esteem, respect for others, understanding others and potential tolerance of mistakes. All these characteristics can contribute actively to school learning.

Thirdly, more and more tasks of educational organizations require teamwork. To work together effectively, team spirit seems more significant. The face-to-face relationships among members of the groups are a vital element of teamwork. Collaborative skills, supportive one another, and rapport of working relationships are all the basis of the team spirit to achieve the, desired outcomes.

Above all, it is obvious that interpersonal skills at work in educational organizations are important and getting more important. Interpersonal skills are important not just for the personal growth of the individual, such as empathy, warmth, engagement, respect (with pupils as well as colleagues), openness, honesty, transparency and trust but also for the development of educational organizations, such as ethos, climates, and cultures. To a greater extent, strong interpersonal skills make an educational organization a happy place with a sense of purposeful behaviours.

\section{Case Study---Interpersonal Skills in Educational Context}

Educational organizations are more aware than ever before of interpersonal skills, especially when interactive behaviours are displayed defectively. So to exemplify the workings of interpersonal skills, some examples will be given: teachers and students; teachers and teachers; teachers and leaders. 


\section{Teachers and Students}

The interpersonal relationship between teachers and students is the most explicit and common issue directly concerned with the basic activity in a school...teaching and learning. The example here is taken from an experience of a teacher in a middle schoo1.

Qing is a 15 year-old girl, whose parents divorced, living with her grandmother. She had a dramatic decline in her performance a few weeks ago. Mrs Zhang, the teacher in charge of the class called her to the teacher's office because she wanted to help her student with the problems facing her. Mrs Zhang started the conversation like this:

"Hello, sit down, please. I'm here just to see if you have been any problems with

your study. Your study's been working well, hasn't it?"

"Well, yes, I suppose it has, but I've been a bit worried sometimes..."

"Well, to be frank, I'd like to give you some advice about your study..."

How do we assess these reactions? Mrs Zhang obviously did not recognize certain details, which were significant in this conversation.

Firstly, it is related to speaking and probing skills. The opening like "I'm here just to see if you have been any problems with your study" was rather abrupt and made the goal of conversation quite facile, which mad the student feel that the teacher was only interested in any practical problems she was experiencing with her study. As a result, the student did not feel she could express her more fundamental problems as this would take too much time and was not appropriate. Undoubtedly, the teacher would have been very enthusiastic to get more information from the student about the problem.

Secondly, it concerns listening and empathy skills. The teacher failed to observe signs of worry and distress in the student's answers. For example, when the student said, "well, yes, I suppose it has, but I've been a bit worried sometimes..."The teacher seized "suppose it has" and ignored the cue "a bit worried".

Thirdly, it is about understanding others' skills. The teacher failed to attend to the student and interpret verbal and non-verbal cues she provided; for example, the teacher should get more from "I've been a bit worried..."such as the tone, the facial expressions, stances as well as her personality etc.

So this teacher displayed deficient communication and understanding skills in the interactive behaviours with the student. That directly influenced the achievement of the desired outcomes to help the student with the difficulties she was facing.

\section{Leader and Teachers in a Team}

In a school, more and more tasks require teamwork. Effective interpersonal skills are a pivot for every aspect of group functioning.

The strong existence of a group greatly depends on communication, on exchanging information and transmitting meaning, on the understanding of one another in a group. Here is an example of group work from an experience by a team leader who was responsible for the academic group.

In this group, there are six members engaged in the same subject teaching in the same grade. Some are the' experts'. They are older and have a lot of practical teaching experience in the classroom but most only have lower qualifications in this area. While the team leader has higher formal qualifications than they do, to establish the respectful, trustful relationship in a team, she tried to make members comfortable with her. She usually gave some suggestions with "Perhaps you could do so and so". "I have seen such and such and it seemed a good idea" instead of "What you should do is..." Because this group of teachers are very confident in what they are doing and she does not want to upset them as they have a lot of practical advice that she can share with them.

Last but not least, they hardly use computers and information technology as a teaching method in a classroom. Obviously, it is clear how they would feel when the young team leader came straight in and told them what they should and should not do. What does she do? She believed in offering support whenever they were in need of help and wherever they were, in the staff room, classroom or the corridor. That really contributed to the achievement of the desired outcomes. 
Successful communication skills and, understanding skills as well as awareness of self and others' skills merged in this academic team. This example illustrates a problem, which confronts many team leaders or teachers occupying professional roles in schools. The advice and judgments always have a dramatic effect on the teamwork.

\section{Conclusion}

This paper has been concerned with the literatures of concepts and components of interpersonal skills, or namely social skills which individuals employ in order to achieve their goals and desired outcomes in everyday social life. The skills selected in this paper are: communication skills, including speaking, listening, attending, empathy, probing etc. skills; understanding others skills, including interpreting verbal and non-verbal cues, making attributions, forming judgments and impressions and thinking about how the other person may be 'framing' etc. skills; awareness of self and others skills. Although, this selection is not exhaustive, the skills included do represent the core elements of interpersonal skills. This paper also provides a clear comprehensive overview of the interpersonal skills essential for effective functioning in an educational context. Some utilisations of interpersonal skills in the educational organisation are presented and analysed with the interpersonal relationships between teachers and students as well as teachers and team leaders in a group. The aim of this paper is to facilitate the awareness, importance and development of interpersonal skills in the $21^{\text {st }}$ century.

\section{References}

[1] Burgoon, M., Hunsaker, G F. and Dawson, J.E.1 994.Human Communication, (3m edition) SAGE Publications.

[2] Duck, S. 1998. Human Relationships, (3m edition) SAGE Publications.

[3] Fontana, D. (1990) Social Skills at Work, London, Routledge.

[4] Furnham, A. (1997) The psychology of Behaviour at Work: the individual in the organisation, Hove, Psychology Press.

[5] Guirdham, M. (2002) Interpersonal behaviour at Work (3m edition), London, Prentice Hall.

[6] Hargie, O., Saunders, C. and Dickson, D. 1994. Social Skills in Interpersonal Communication (3rd edition) Routledge London and New York.

[7] Hunt, J.W. (1992) Managing People at work,(3rd edition) London, McGraw. Hill.

[8] Hayes, J. (2002) Interpersonal Skills at Work (2rd edition), London, Routledge.

[9] Information Age 2004 Holistic Education Essential-To A Degree.

http : // www.Infoage.idg.com.au/index.php/id;102750 1097; fp;4;fpid;404956636

[10]Lewis, M. 2005 Handouts Session 5 Interpersonal communication skills: effective interpersonal relationships and interactive behavior.

[11]The enGauge 21st Century Skills 2003 Interpersonal Skills, http://www.ncrel.org/engauge/kills/effcomm2.htm

[12]West, M. A. (ed) (1996) Handbook of Work Group Psychology, Chichester, John Wiley.

\section{Bibliography}

[1] AmoId, J., Cooper, C. L. and Robertson, I.T. (1998) Work Psychology: Understanding human behaviour in the workplace, ( $3^{\text {rd }}$ edition) London, Pearson.

[2] Forrest, J. and Knasel, E. 1989. Interpersonal skills At Work, National Extansion College 
[3] Hayes, J. (2002)/Interpersonal Skills At Work (2nd edition), London, Routledge.

[4] Nias, J., Southworth, G and Yeomans, R. 1989.Staff relationship in the Primary School,Cassell.

[5] Johnson, D. W. and Johnson, F. P. (1997) Joining Together: Group Theory and Group Skills, (6rd edition), Boston, Allyn and Bacon. 